\title{
EPIGENETICS: THE FUNCTIONAL MEMORY OF RIBOSOMAL GENES
}

\author{
Wanda S. Viegas ${ }^{1}$, Manuela Silva ${ }^{1}$ and Nuno Neves ${ }^{1,2}$ \\ ${ }^{1}$ Instituto Superior de Agronomia, Centro de Botânica Aplicada à Agricultura, Tapada da \\ Ajuda, 1349-017 Lisboa, Portugal, phone+351213653281, wandaviegas@isa.utl.pt \\ ${ }^{2}$ Secção Autónoma de Biotecnologia, Faculdade de Ciências e Tecnologia, Universidade \\ Nova de Lisboa, Caparica, Portugal. \\ Abstract: The functional importance of Epigenetics arise from DNA sequencing \\ programs that show the need for another code to explain the dynamics of gene \\ expression patterns observed along cell differentiation and organism \\ development. In this context, the study of ribosomal gene silencing is in fact \\ an excellent model to better understand the relationships that are established \\ between gene transcription and chromatin topology, and to unravel the \\ epigenetic switches evolved in the framework of gene expression.
}

Key words: Epigenetics, Nucleolar Dominance, DNA methylation, Histone code

\section{INTRODUCTION}

During the last decade Genomics revealed the complete code of genetic information of an increasing number of organisms. Although DNA sequencing programs are giving us important catalogues of protein coding genes, it is becoming increasingly evident that sequence information alone is not sufficient to understand how the genome is interpreted in a living cell. In this context, the study of functional information has emerged in a new mode as Epigenetics. Epigenetics relies on the identification of heritable gene expression patterns, and the mechanisms associated with their modifications without changes at the DNA sequence level. This reflects the importance of epigenetics, since chromatin itself carries additional information that does not reside in the nucleotide sequence, as was postulated by Conrad Waddington [1]. Since then, several studies in animals, plants and yeast 
disclosed the basic "epigenetic rules', where condensed heterochromatin represents a potent gene silencing capacity due to its tight conformation, in contrast to the relaxed configuration of euchromatin, available for transcription (Fig.1).

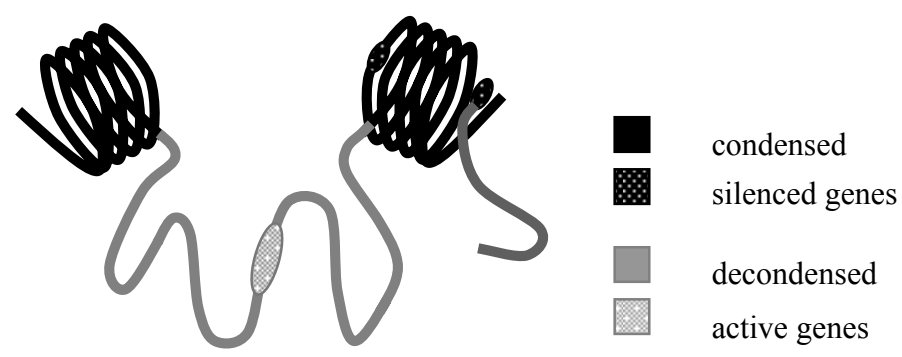

Figure 1. Condensed heterochromatin corresponds to a gene silencing state and a tight conformation, contrasting with euchromatin which is potentially active and showing a relaxed configuration.

Those features set the idea of an epigenetic code that helps in shaping chromatin topology and, consequently, gene expression patterns. In this context the study of ribosomal RNA gene expression, and its organization patterns, is fundamental to the growing understanding of epigenetic pathways that rule chromatin remodeling events.

\section{ORGANIZATION OF RIBOSOMAL CHROMATIN: FUNCTIONAL AND STRUCTURAL DOMAINS}

Ribosomal RNA genes (rRNA) are considered as the genes coding for three of the four RNA molecules needed to build up ribosomal sub-units, in association with a large number of different proteins. Each ribosomal gene encodes the information for a large $45 \mathrm{~S}$ primary transcript which is further processed into $18 \mathrm{~S}, 5.8 \mathrm{~S}$ and $25 \mathrm{~S}$ rRNA molecules. Ribosomal genes are present in multiple copies organized in tandem, with each gene unit separated from the next by intergenic spacers (Fig.2A). Multiple ribosomal DNA copies are clustered at particular chromosomal loci termed NORs (Nucleolar Organizing Regions), since the transcription of the rDNA units fabricates the most conspicuous nuclear compartment - the nucleolus, where the assemblage of ribosomal sub-units takes place. The analysis of ribosomal chromatin organization soon suggested that only particular arrays of rDNA units in a NOR are active, as demonstrated by classical studies showing a sub-set of ribosomal RNA genes engaged in RNA polymerase I 
elongation complexes [2]. Several studies using in situ hybridization (ISH) with ribosomal probes extensively confirmed [3 - 4] two distinct chromatin domains within each NOR: a large condensed perinucleolar block followed by thin intranucleolar strands (Fig.2B), representing the differential regulation of the excessive number of rRNA genes per cell through internal changes in chromatin organization.

A

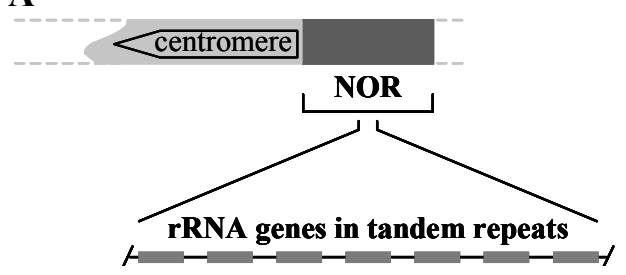

B

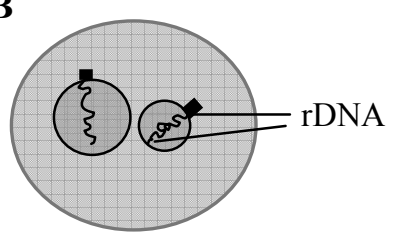

Figure 2. Ribosomal genes are organized in multiple DNA copies clustered at particular chromosomal loci termed NORs (Nucleolar Organizing Regions) (A). Distinct functional chromatin domains are observed within each NOR (B). The condensed perinucleolar block corresponds to the excessive number of inactive rRNA genes, and the thin intranucleolar strands to the potentially active ones.

\section{NUCLEOLAR DOMINANCE: A CASE STUDY IN EPIGENETICS}

Nucleolar dominance was initially described by Navashin [5] in Crepis spp. hybrids, representing a genomic interaction where NORs of one parental species are silenced; hence, these NORs comprise only one continuous condensed domain. Navashin demonstrated that nucleolar dominance is a reversible process, since when the hybrid is backcrossed to the parent which contributed the chromosome with the silenced NOR, the activity of this NOR is restored in the backcross plant in which it is carried. This effect was later confirmed in a number of other plant and animal species, showing that permanent damage or loss of silenced NORs does not occur, prompting this phenomenon to an epigenetic interpretation. In this context, two allopolyploid species, Triticosecale (triticale) and Arabidopsis suecica, with marked differences in their DNA content and origin (Fig.3) are currently used to disclose epigenetic marks and their developmental dynamics. Triticale is a synthetic allopolyploid resulting from experimental crosses between wheat (Triticum aestivum $\mathrm{L} ., 2 \mathrm{n}=42$ ) and rye (Secale cereale L., $2 \mathrm{n}=14$ ), both with large genomes. Arabidopsis suecica is a natural allopolyploid with parental genomes originating from A. arenosa $(4 \mathrm{n}=32)$ and $A$. thaliana $(2 \mathrm{n}=10)$, which have very small sizes. 


\section{Triticum aestivum x Secale cereale $\underset{\text { Triticosecale }}{\downarrow}$} (synthetic polyploid)

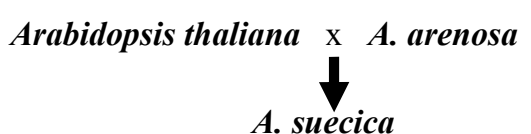

(natural polyploid)

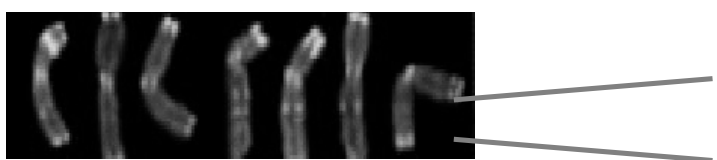

S. cereale $(\mathrm{n}=7)$ $7000 \mathrm{Mpb} / 1 \mathrm{C}$

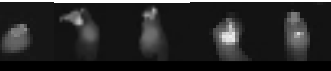

A. thaliana $(\mathrm{n}=5)$

$120 \mathrm{Mpb} / 1 \mathrm{C}$

Figure 3. Allopolyploid species - Triticosecale and A. suecica - are fertile hybrids with different parental genomes sharing the same nuclear environment, but having a common cytoplasm. Nucleolar dominance occurs with silencing of the rRNA genes from $S$. cereale and $A$. thaliana origin respectively, although the DNA content of both species is dramatically different. The DNA content of the haploid genome of $A$. thaliana corresponds to less than a chromosome arm of $S$. cereale.

Analysis of the ribosomal chromatin organization and expression features revealed silencing of ribosomal genes of rye origin in triticale, and of $A$. thaliana origin in A.suecica [6]. Moreover a marked developmental regulation of nucleolar dominance was disclosed, through the characterization of the exact moments in which that process is established and further reprogrammed, as exemplified for triticale in Fig. 4. The evaluation of rye NOR expression patterns in triticale was performed in developing seeds, revealing that nucleolar dominance is simultaneously established short after pollination both in the embryo and in the endosperm, indicating a total independence of the number of previous cell cycles [7]. Silencing of NORs in triticale is maintained during the development of the sporophyte and is then reprogrammed during meiosis.[8].

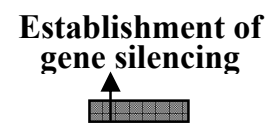

Embryogenesis

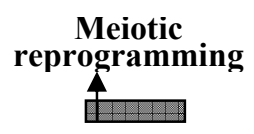

Gametogenesis

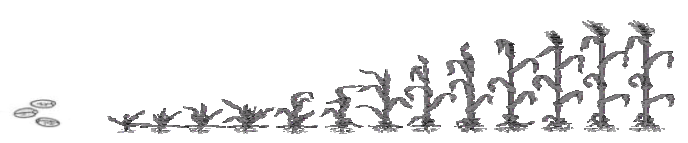

Figure 4. In Triticale nucleolar dominance is established during embryogenesis and erased at meiosis 


\section{EPIGENETIC MODULATION OF NUCLEOLAR DOMINANCE}

The first epigenetic mark, shown to be responsible for particular ribosomal chromatin states, and changes in gene expression patterns [9], was the chemical modification of cytosines in $\mathrm{CpG}$ or $\mathrm{CpNpG}$ nucleotide sequences, mediated by DNA methyltransferases. These enzymes are capable of adding a methyl group de novo in both DNA strands, or maintaining the previously established methylation pattern by methylation of newly formed DNA strands after DNA replication. Several studies inducing DNA hypomethylation in many hybrids demonstrated, at both the cytological as at the molecular level, the erasing of nucleolar dominance and the consequent activity of NORs from any parental origin [10]. This direct correlation between the differential heterochromatinization of NORs of one parental origin in hybrids, DNA methylation at cytosine residues and the switching off of rDNA units, clearly establishes the epigenomic origin of nucleolar dominance. Other epigenetic tags usually associated with chromatin remodeling are the various histone post-translation modifications, which can occur in nucleosomes. Histone modification occurs mainly on their tails, and are associated with the acetylation, methylation, phosphorylation, ribosylation or ubiquitination of particular aminoacids residues. These histone marks lead to marked modifications in chromatin organization patterns and to changes in nuclear topology of specific chromatin domains. Disclosure of the "histone code" associated with nucleolar dominance in hybrids was performed through identification of distinct modified histones on NORs from both parental species that associate with active or silent rDNA arrays.

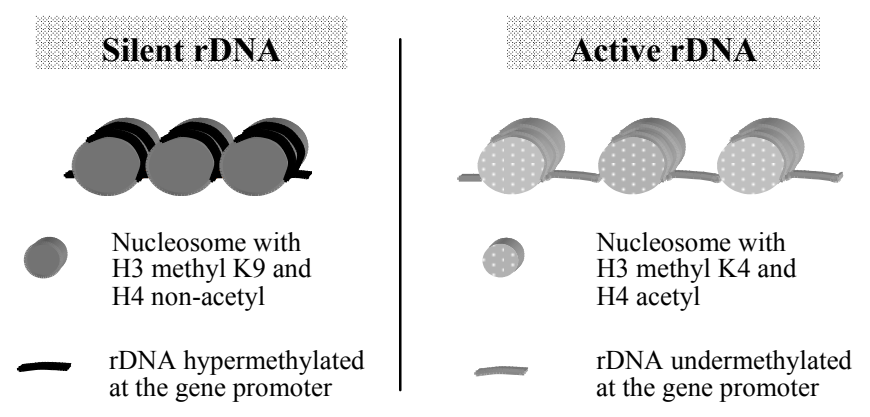

Figure 5. Distinct epigenetic tags are associated with differential transcription states of ribosomal chromatin. 
These in-depth chromatin characterizations revealed that heterochromatic rDNA domains display densely methylated DNA sequences, present low levels of histones $\mathrm{H} 4$ acetylation, and also have an identifiable mark on histones $\mathrm{H} 3$ which are methylated at lysine 9 residues. Conversely, ribosomal euchromatin, where active rRNA genes reside, correspond to decondensed chromatin with mostly unmethylated DNA sequences, enriched in acetylated histones $\mathrm{H} 4$ and with distinctive methylation at lysine 4 residues of histones H3 (Fig. 5) [11].

Interconversions between ribosomal genes expression patterns are mediated by several chromatin remodeling enzymes which are being searched for using RNA interference technology to generate loss-of-function mutant lines. Some important enzymes responsible for the establishment and the maintenance of nucleolar dominance were already identified and are directly related with dynamics of epigenetic marks [11].

\section{ACKNOWLEDGEMENTS}

We would like to express our sincere thanks to Margarida Delgado for her inspirational help in producing the figures.

\section{REFERENCES}

1. Waddington, $\mathrm{C} \mathrm{H}$. "Canalization of development and the inheritance of acquired characters”, Nature, vol. 150, pp. 563-565, 1942.

2. Miller G, Berlowitz L, Regelson W. "Chromatin and histones in mealy bug cell explants: activation and decondensation of facultative heterochromatin by a synthetic polyanion", Chromosoma, vol. 32, pp. 251-261, 1971.

3. Caperta A, Neves N, Morais-Cecílio L, Malhó R, Viegas W. "Genome restructuring in rye affects the expression, organization and disposition of homologous rDNA loci" $J$. Cell Sci vol. 115, pp. 2839-2846, 2002.

4. Pontes O, Lawrence RJ, Neves N, Silva M, Lee J-H, Chen ZJ, Viegas W, Pikaard CS "Natural variation in nucleolar dominance reveals the relationship between nucleolus organizer chromatin topology and rRNA gene transcription in Arabidopsis" Proc Natl Acad Sci USA, vol. 100, pp.11418-11423, 2003.

5. Navashin M. "Chromosomal alterations caused by hybridization and their bearing upon certain general genetic problems" Cytologia, vol. 5, pp. 169-203, 1934.

6. Viegas W, Neves N, Silva M, Caperta A, Morais-Cecílio L. "Nucleolar dominance: a 'David and Goliath' chromatin imprinting process" Curr Genomics, vol. 3, pp. 563-576, 2002.

7. Castilho A, Queiroz A, Silva M, Barão A, Neves N, Viegas W. "The developmental stage of inactivation of rye origin rRNA genes in the embryo and endosperm of wheat $\mathrm{x}$ rye F1 hybrids" Chrom Res, vol. 3, pp. 169-174, 1995. 
8. Silva M, Queiroz A, Neves N, Barão A, Castilho A, Morais-Cecílio L, Viegas W. "Reprogramming of rye rDNA in triticale during microsporogenesis" Chrom Res, vol. 3, 492-496, 1995.

9. Neves N, Castilho A, Silva M, Heslop-Harrison JS, Viegas W. "Genomic interactions: gene expression, DNA methylation and nuclear architecture" Chrom Today, vol. 12, pp. 182-200, 1997.

10. Pikaard CS. "The epigenetics of nucleolar dominance" Trends Genet, vol. 16, 495-500, 2000.

11. Lawrence RJ, Earley K, Pontes O, Silva M, Chen ZJ, Neves N, Viegas W, Pikaard CS. "A concerted DNA methylation/histone methylation switch controlling rRNA gene dosage control and nucleolar dominance" Molecular Cell, vol. 13, 599-609, 2004. 